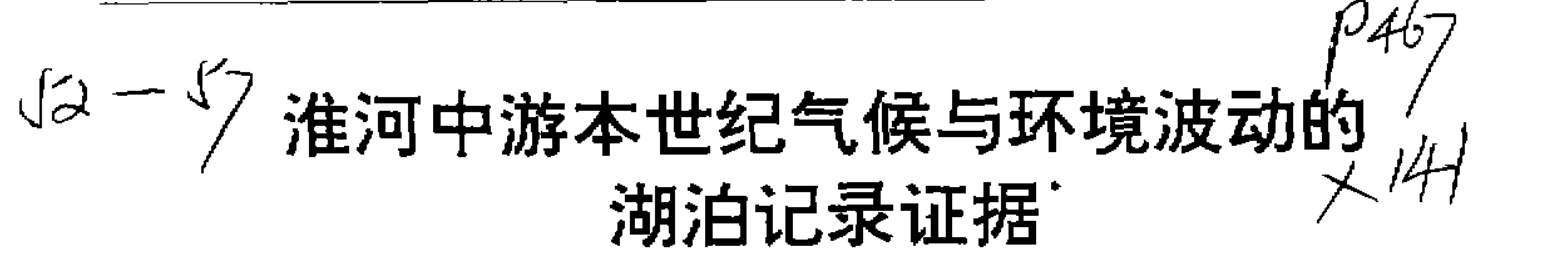

\author{
王云飞夏威岗 ${ }^{1}$ 潘红禾 $^{1}$ 杨世蓉 $^{2}$ 胡守云 ${ }^{1}$

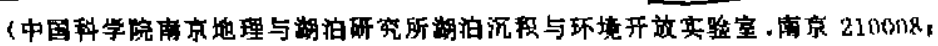 \\ 2 ; 中国科学院南京地质与古生物研究所, 南京210008
}

堤要为研然本世纪淮河中游气埃与坏境波动的湖泊沉积响应,1991 秋季在女山湖湖心 提取了 $4.8 \mathrm{~m}$ 沉积物. 对顶部 $20 \mathrm{~cm}$ 沉积物运用 ${ }^{210} \mathrm{~Pb} 、{ }^{137} \mathrm{Cs}$ 的年代定位、获得 $1904-1991$ 年湖泊沉 积物的年序. 以此通过高分辣沉积记录的代用标志提取, 重建了本世纪女山湖气接与环境的变化 过程、结果表明、本世纪最初20-30 年女山湖地区温度偏低、湿度偏大 140.50 年代为本世纪温度 最高的时段.50至 60 年代中期为延续最长的偏显时段、温度在 60 年代一度降低.70 年代中期后

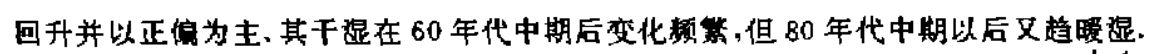
关䭪调
分类号

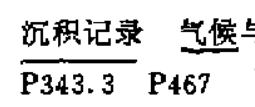$$
\text { 1904-1991 年 女山湖 }
$$

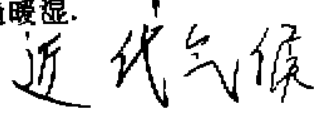

根据器测资料和文字记录仍然是近代气候与环境重建的基本方法. 但我国大多数地区 50 年代以后才有系统的观察数据; 中西部许多地区因台站分布不均缺少资料的情况也很普遍, 往 往难以获得满意结果. 利用湖泊的地域分布广和沉积物保存信息量丰富的特点进行高分辩环 境代用标志提取和辩析可获得区域气候与环境波动的新证据. 本文以淮河中游女山湖为例、用 湖泊沉积学方法,对本世纪该地区的气候与环境波动过程作简要分标.

\title{
1 女山湖概况
}

女山湖位于安碳省明光市北部,坐标 $32^{\circ} 50^{\prime}-33^{\circ} 02^{\prime} \mathrm{N} 、 117^{\circ} 58^{\prime}-118^{\circ} 14^{\prime} \mathrm{E}$ 之间. 经本次考 察和实测, 当湖面高程 $13.5 \mathrm{~m}$ 时,面积 $104.6 \mathrm{~km}^{2}$, 平均水深 $1.7 \mathrm{~m}$, 最大水深 $2.4 \mathrm{~m}$, 容积 1.78 $\times 10^{8} \mathrm{~m}^{3}$ (图 1)，女山湖汇水面积 $4185 \mathrm{~km}^{2}$, 主要的人湖菏流池河从南部流人, 全长 $17 \mathrm{~km}$ ，多 年平均经流量 $5.82 \times 10^{\mathrm{B}} \mathrm{m}^{\mathrm{3}} / \mathrm{a}$, 人湖泥沙量 $51.6 \times 10^{4} \mathrm{~T} / \mathrm{a}$. 湖泊出流位于东北部旧县, 经七里 湖注人淮河. 1982 年在旧县兴建女山湖大闸, 湖泊开始受人工调控.

湖盆发育在搂庐断翌带中,外形呈现 NNE-SSW 走向、四周被海拨 40-90m 的丘陵、岗 地包围. 女山位于湖东北岸, 高程 $93 \mathrm{~m}$, 为第四纪玄武岩火山口,其西延形成祁咀一高咀水下平 台, 成为湖泊出流的门㩜. 因此女山湖即使入湖径流很少、湖心也维持湖沼环境. 据光明市郊钻 孔资料和实测平均沉积速率 $2.24 \mathrm{~mm} / \mathrm{a}$ 推算, 女山湖于中全新世因地壳断陷形成. 是我国东部 地区为数不多的发育历史较长、湖泊沉积连续的现代湖泊, 也是进行古气候重建理想地区.

湖区位淮河两岸嗳温带与北亚热带过渡带,年平均气温 $15 \mathrm{C}$,无罧期 219 天,年平均降水

- 国家自然科学基金助项目 (49271068)，收期:1998-01-04. 壬云飞、男.1940年生、研究员.

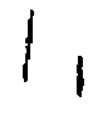




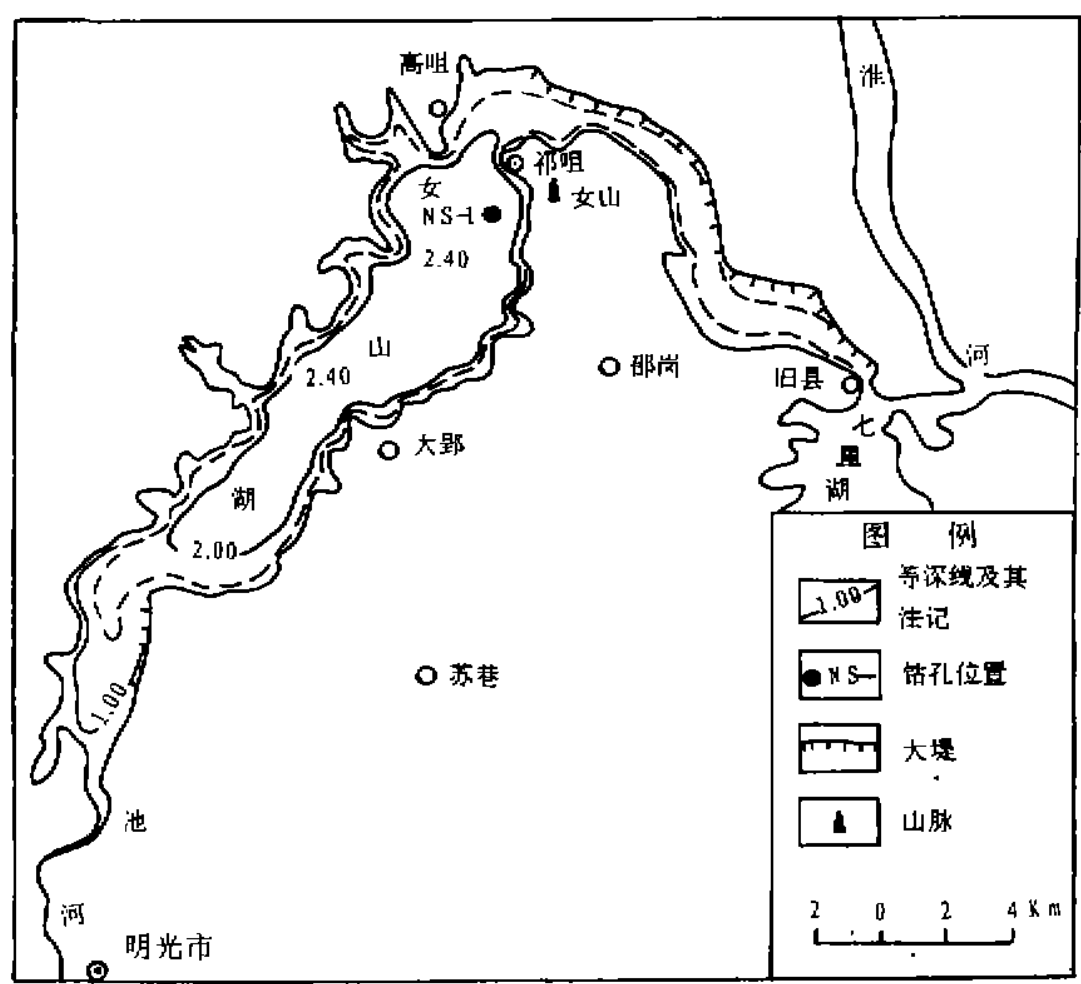

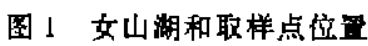

Fig. I Location of Nushan Lake and sampling site (NS-1)

量 $939.9 \mathrm{~mm}$ ，属半湿河温和气候.

\section{2 采样与实验分析}

\section{1 采样}

采样点选择湖东北部女山附近湖心, 坐标 $33^{\circ} 0^{\prime} 13.4^{\prime \prime} \mathrm{N}, 118^{\circ} 7^{\prime} 21.5^{\prime \prime} \mathrm{E}$. 水深 $2.3 \mathrm{~m}$. 于 1991 年 11 月实施, 使用美国活塞式采样器, 共连续采集岩心 $4.8 \mathrm{~m}$, 定名 NS-1 孔. 顶部 $20 \mathrm{~cm}$ 为本 文研究层段、样品按 $1 \mathrm{~cm}$ 和 $2 \mathrm{~cm}$ 间隔取样分析.

\section{2 建立剖面年序}

测年采用 ${ }^{131} \mathrm{Cs}$ 和 ${ }^{210} \mathrm{~Pb}$ 沉积速率测定和断年 ${ }^{[1]}$. 样品间隔 $1 \mathrm{~cm}$, 经硝化提取样液后用低本 底 $\alpha$ 能谱仪 (1024 道) 测试. ${ }^{197} \mathrm{Cs}$ 是核爆炸后的裂变产物，其峰值对应 1986 年切尔诺贝利核泄 漏事件和 1963 年全球大气层核试验高峰 ${ }^{[2]} .{ }^{210} \mathrm{~Pb}$ 为天然放射铀系元素一员、在湖泊沉积的自 我封闭体系中, 按半衰期 $22.3 \mathrm{a}$ 有规律衰减, 经计算求得不同深度年代. 剖面 $19.5 \mathrm{~cm}$ 处对应 测年底界 1904 年(图 2).

\section{3 代用标志的实验方法和环境意义}

研究工作选择的指标: 沉积速率、岩性、磁化率; 有机质含量、色素和硅藻. 研究层段的岩性 均为含粉砂质粘土, 故以小于 $8 \phi$ 的粘粒 (CL) 和 8-4申的粉砂 (SL) 含量表示. 其方法是将原样 
制成油浸落片, 用偏光显微镜统计粘土和粉砂含量. 女山湖在丰水时段湖泊沉积物以粘土为 主,但淮河洪灾时的泥砂倒䧿和干旱时段东岸泥砂输入可使沉积物粗化.

低频磁化率 $\left(\chi_{L F}\right)$ 和频率磁化率 $\left(\chi_{\text {Id }}\right)$ 分析使用英国 MS2 型磁化率仪和 MS2B 双频探头测 定. 沉积物中 $\mathrm{X}_{\mathrm{L}}$ 的贡献主要来源于入湖玄武岩风化物多寒、 $x_{\mathrm{rd}}$ 反映细粘滞性颗粒的浓度变

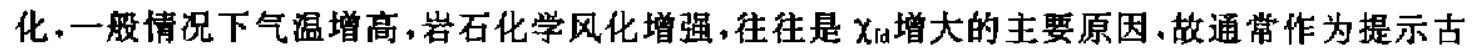
气候气温变化的代用指标 ${ }^{[3]}$.

有机质含量 (LO1) 以 $550^{\circ} \mathrm{C}$ 烧失量表示,但它是一个混合信息, 目前倾向用色素含量和不 同的比值来评价湖泊环境. 色素分析采用 $90 \%$ 丙酮萃取和测量萃取液的吸光值, 分别计算叶 绿素及其衍生物 $(C D)$ 、总类胡罗卜素 $(T C)$ 、西藻黄素 $\left(\mathrm{O}_{\mathrm{sC}}\right)$ 和蓝㩰叶黄素 $\left(\mathrm{M}_{\mathrm{Yx}}\right)$ 含量. $\mathrm{CD} / \mathrm{TC}$ 通常指示湖泊营养状况和外源有机质的输入强度, 是揭示古湿度变化的较好指标; $\mathrm{O}_{\mathrm{sc}} / \mathrm{M}_{\mathrm{YX}}$ 多 反映蓝藻植物组合变化,并常结合硅藻研究用于综合评价内源有机质含量和富营养化趋势 ${ }^{[4]}$. 硅落分析采用古生物学方法提取和鉴定.其组合和丰度可直接进行环境分析.

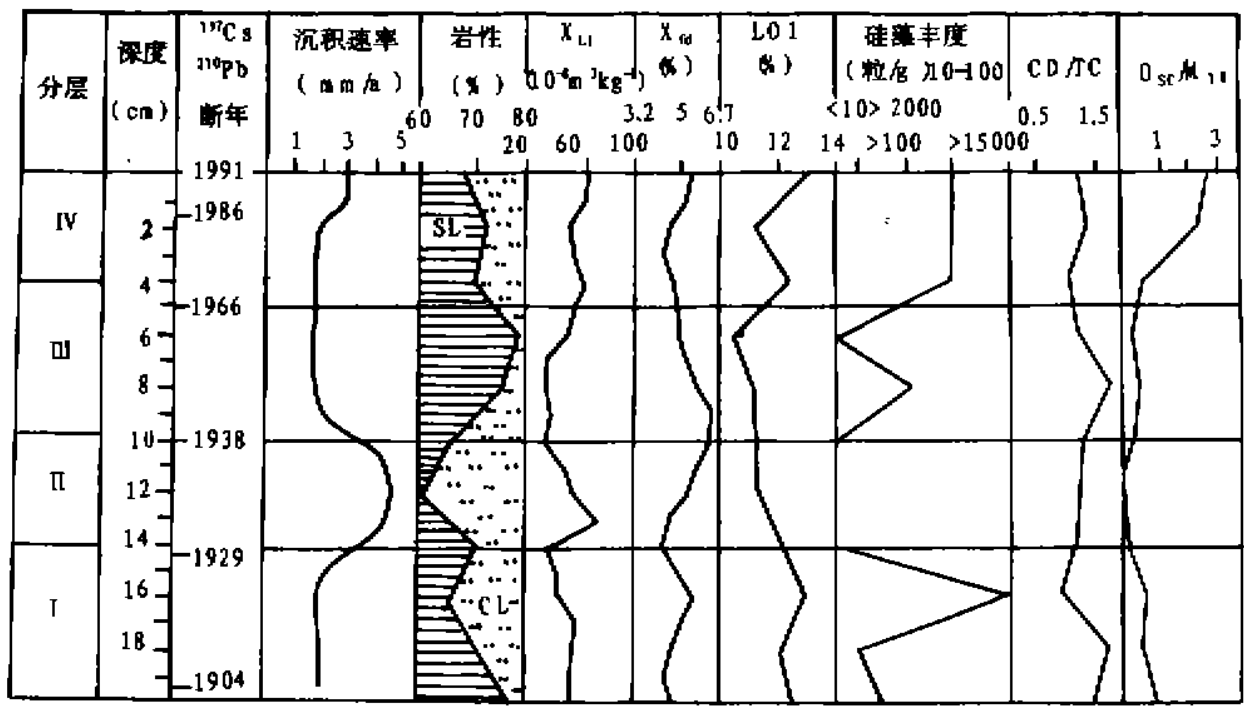

图 2 NS-1 孔环境代用标志的垂向变化

Fig. 2 Vertical change of environmental proxits of $\mathrm{NS}-1$

\section{3 分析结果和气候与环境重建}

根据各项指标的分析结果和变化特征,研究剖面可分为四段(图 2).

(1) 第 $\mathrm{I}$ 段 $(19.5-14 \mathrm{~cm}, 1904-1930$ 年): 沉积环境以 $17 \mathrm{~cm}$ 为界,下部沉积速率较小 $(2 \mathrm{~mm} / \mathrm{a}) 、 \mathrm{CL}$ 大于 $70 \%, \mathrm{LOl}$ 和 $\mathrm{CD} / \mathrm{TC}$ 均较高、表明外源有机质的贡献较大. 又 $\chi_{\mathrm{L}}$ 偏小，反 映池河入湖水量较丰富、姑小于 5 ,分析本世纪最初的 20 多年平均温度偏低. 上部 $16 \mathrm{~cm}$ 处硅 藻丰度高、以颗粒直链渠 Melosira granulata 为优势种、其含量占总量的 $85 \%$. 另据 LO1 含量 较高但 CD/TC 降低和 $\chi_{\text {[d }}$ 增大,辩析 20 年代以后入湖经流渐偏少但气温比下部增高.区域偏 干导致湖泊收缩和短时期湖泊富营养化增强.

（2）第II 段 $(14-10 \mathrm{~cm}, 1930-1938$ 年)：该段平均沉积速率从 $2 \mathrm{~mm} / \mathrm{a}$ 增高至 $4.8 \mathrm{~mm} / \mathrm{a}$. 
相应沉积物 $\mathrm{CL}$ 最低，含来源于淮河流域的粗粉砂. $\chi_{1 F}$ 底部低, $13 \mathrm{~cm}$ 处达峰值, 反映湖泊收缩. 玄武岩物源贡献增强; $\chi_{10}$ 底部低向上逐渐增大至峰值. $\mathrm{LOI}$ 底部较高向上递减; $\mathrm{CD} / \mathrm{T}$ 为低值. 全段硅藻丰度小于 10 粒 $/ \mathrm{g}, \mathrm{O}_{\mathrm{Sc}} / \mathrm{M}_{\mathrm{Yx}}$ 在 $12 \mathrm{~cm}$ 处达低谷, 表明湖泊环境变化较大、内源有机质 含量低. 揭示, 1930 年前后本区从温度偏低、降水较丰富转变为温度持续增高、降水偏少的环 境. 另从环境代用标志存在的不协调, 反映人类活动影响较强,其中包括 1931 年淮河流域特大 洪水和 1938 年黄河夺淮等灾害事件,使外流域涊沙大量倒灌入湖.造成偏干旱气候背景下高 沉积速率.

（3）第段(10-5cm,1938-1966 年): 本段沉积速率偏小 $1.8 \mathrm{~mm} / \mathrm{a}, \mathrm{CL}$ 最大. X X 和 LOI 偏低,但 $\chi_{\text {Id }}$ 为高值区向上稍有递减. $\mathrm{CD} / \mathrm{TC}$ 全段偏高,在 $8 \mathrm{~cm}$ 处达峰值表明外源有机质丰富. 反映该时段温度偏高,降水和入湖径流较丰富. 另从 $\mathrm{O}_{\mathrm{sc}} / \mathrm{M}_{\mathrm{Yx}}$ 全段变化不大,反映湖泊环境较 为稳定, 揭示 50 年代以后人类活动的影响虽然增强，但湖泊上游的水库和治淮工程发挥了效 益.

（4）第 N 段 (5-Ocm, 1966-1991 年): 该段非有机指标 X(d反映下部年均温度偏低,向上增 高 ${ }_{3} \mathrm{CL}$ 和 $\chi_{\mathrm{LF}}$ 变化反映降水和入湖径流上、下部偏少, 中部较多、但有机指标 $\mathrm{O}_{\mathrm{SC}} / \mathrm{M}_{\mathrm{YX}}$ 显示蓝藻 㨁物群落急剧变化,内源生物量明显增高. 另硅藻丰度增大全段保持 2000 粒 $/ \mathrm{g}$,组成以颗粒直 链营为主,包括脆杆藻 Fragilaria sp.、小环落 Cycloteaal sp. 等生性于富莒养化水体的种 群 ${ }^{[5]}$. 表明人类活动对水环境影响加剧. 表现在 1982 年旧县建闸储水增强了湖泊封闭性,其次 近年来明光市工业发展使湖泊有机污染和富莒养化日趋严重. 顶部沉积速率增高反映人工控 制后的变化.

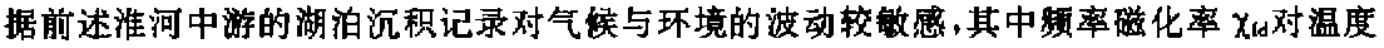
和 $\mathrm{CD} / \mathrm{TC}$ 对千湿波动的响应更灵敏. 为此对这两条曲线进行分级和量化处理并结合其它环 境代用指标作修正,获得本世纪女山湖地区平均温度距平等级变化和干湿等级变化过程 (图 3). 图中显示, 淮河中游的温度波动在本世纪初的 30 年中年平均温度偏低, 其后温度渐升高. 40-50 年代为本世纪平均温度连续较高的时段.60 年代后温度一度递减.70 年代中期后温度 回升进入又一个变暧时段. 由降水、入湖径流、蒸发等引起的湖面变化和干湿波动, 本世纪最初 20 年以偏湿为主, $30-40$ 年代以偏干为主, 50 年代至 60 年代中期为本世纪延续最长的较湿 润时期,其后干湿变化贱繁以偏千为主,80 年代中期以后趋向偏湿.

\section{4 验证与讨论}

女山湖地区缺少系统的器测资料, 为作验证选择明光市气象站资料作为主要对比依据! 该站建于 1956 年,对其 1956-1980 年气诶资料与 1873-1973 年上海气象站长序列资料作比 较后发现 ${ }^{[6]}$, 两地气温的相关系数达 0.892. 由此将明光市平均气温外延获得本世纪前 80 年 的气温过程和 11 年滑动平均值. 但两序列的降水未发现相关性,其干湿判断首先对光明站的 平均降水量的距平值按标准作 5 级划分，1956 年前则根据近期文献记录接历史气候的旱涝分 斿与定级标准整理 ${ }^{[r]}$, 获得旱港等级三年滑动平均序列 (图 4). 将图与湖泊记录的研究结果作 比较,两者的过程和趋势基本相同,显示湖泊记录的近代气候与环境判识的可信性.

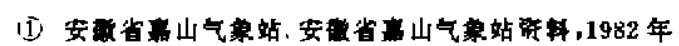




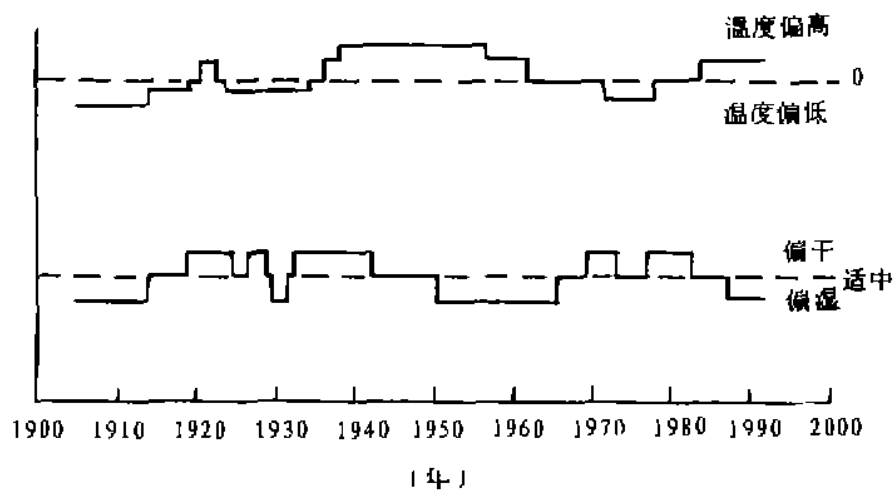

图 3 淮河中游温度距平和干湿波动等级变化

Fig. 3 Schematic diagram of anomalous temperatury and humidity fluctation

(c)

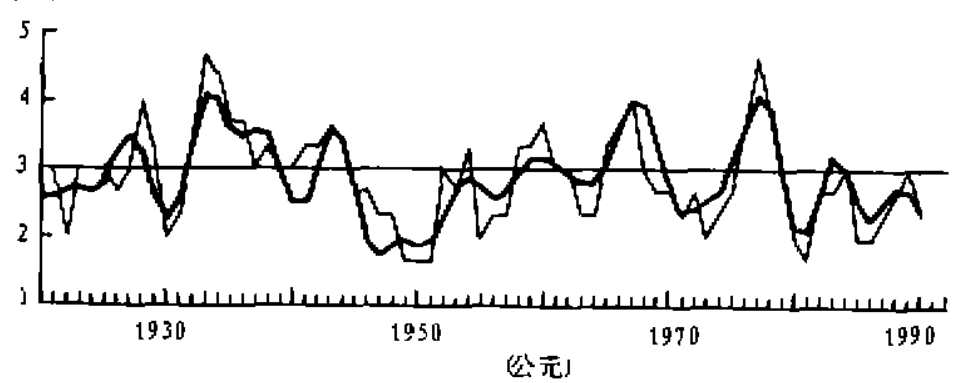

(c)

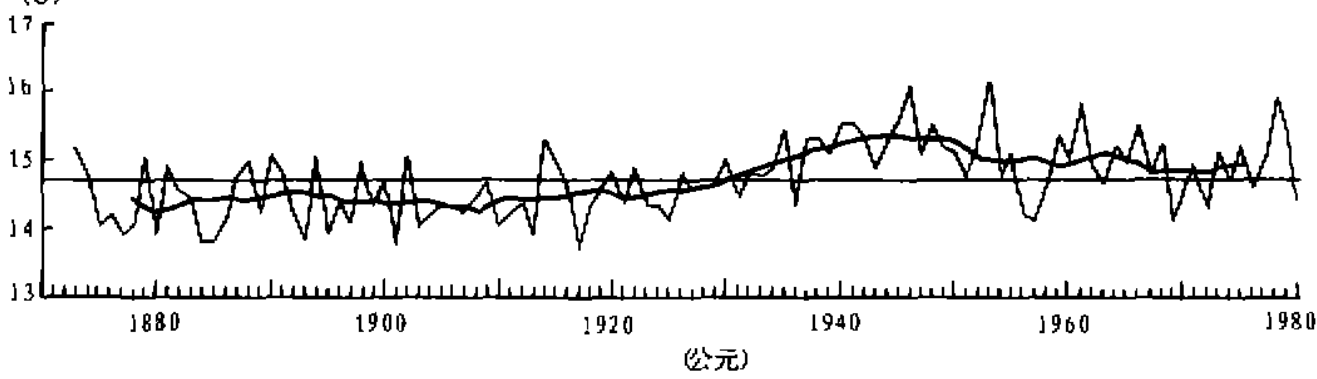

图 4 明光市本世纪早满等级和气盓变化

Fig. 4 The reconstaction of temperature and humidity of Minguang city in the 20th century

!, 旱港变化过程 (细线为 3 年滑动平均值，相线为拟合外推的 3 年滑动平均序列)

2. 气温变化过程 (细线为年平均温度, 粗线为 11 年滑动平均值)

另一方面近代湖泊沉积除受气情等自然因素的影响外,还受人类活动影响.湖泊沉积实际 上记录了人与自然相互作用的信息. 因此部分时段如 30 年代黄河夺淮和水沙倒灌造成的湖泊 快速充填 : 80 年代女山湖出口建闸和明光市排污增大后富营养化发展等显然是人类活动的影 响起了主导作用, 这也是前述两种不同途经获得的结果存有差异的主要原因. 但同时揭示湖泊 沉积记录在分析人类活动的环境影响和研究人地相互作用机制等领域所具有的潜势. 
本研究作为主要代用指标 $\chi_{1 d} 、 \mathrm{CD} / \mathrm{TC}$ 的影响因素较复杂、其变化机制和古气续意义还有 待深入研究. 取样间隔为 $1 \mathrm{~cm} /$ 个和 $2 \mathrm{~cm} /$ 个. 分别代表 4.5 年和 9 年的平均状况. 因此判识的 温度和千湿波动基本上代表了十年级的变化过程.辨析十年内的次级波动较困难.为提高分辨 率, 在今后的研究中选择具有沉积年层的湖泊作深入研究, 预计能获得更满意的结果.

\title{
考文献
}

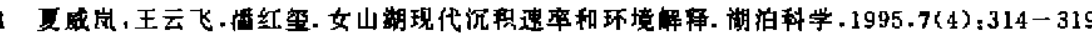

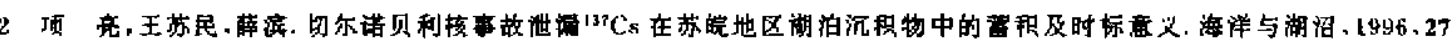
(6): $132-137$

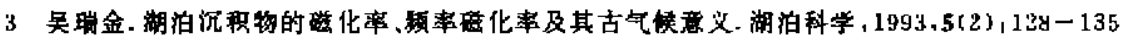

4 Swain E B. Measurement and in terpreation of sedimentary pigments. Freshtrat But 1985 - 15:53-57

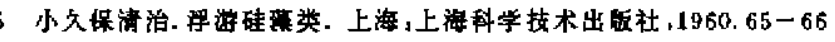

梌家良. 近百年来上海气沮变北的若干特征. 地理学报、1993.48(1),26-31

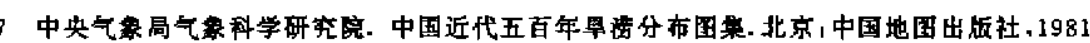

\section{Sedimentary Records of Climatic and Environmental Fluctuation of Middle Reaches of Huaihe River in This Century}

\author{
Wang Yunfei ${ }^{1}$ Xia Weilan ${ }^{1}$ Pan Hongxi ${ }^{1}$ Yang Shirong ${ }^{2}$ Hu Shouyun ${ }^{1}$

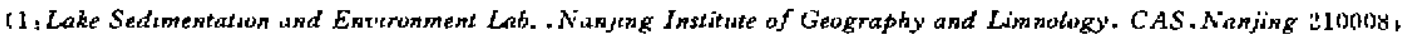 \\ 2 , Nanjing Institute of Geulogy \& Palaeutology. CAS. Nanging 21 uopd
}

\begin{abstract}
The history of climatic and environmental fluctuation of Nushan Lake in this century is reconstructed based on the data of high-resolution climatic and environmental proxies of the lake sediments and the time series of $1904-1991$ buildt up by ${ }^{13} \mathrm{Cs}$ and ${ }^{210} \mathrm{~Pb}$ dating. The results suggest that during the beginning $20-30$ years of this century, there was lower temperature and higher humidity in Nushan Lake area. Then, in the period of the 19401950 's, the temperature reached to the maximum. but cooled down in the 1960's and warmed up after 1970. After then, the humidity changed freguently until the middle of the 1980 's, when the climate in the area became a little humid again.

It is noticeable that the above conclusions coincide with that from the deta of historical and instrumental records of this area. So the method used here can provide evidences for reconstruction of climate and environment change on a short time scale of lack-instrumental records area.
\end{abstract}

Key Words Sedimentary records. climatic and environmental fluctuation. 1904 1991a ,Nushan Lake 